\title{
PENYUSUNAN FUNGSI PRODUKSI TANAMAN JAGUNG
}

\author{
Ovigeria Subroto Sinaga \\ STIE MADANI Balikpapan \\ Email: ovigeria@stiemadani.ac.id
}

\begin{abstract}
Corn is one of the agricultural products commonly handled by farmers. Currently corn is a commodity commodity that is being developed in Kutai Kartanegara Regency through the Corn Revolution movement. The corn revolution movement aims to increase the level of corn production in this district.

One type of corn planted by farmers is sweet corn. This type of corn is preferred by consumers because it has good taste and can be used as raw material to make processed vegetables or directly consumed by boiling or baking.

Farmers in planting corn certainly use various inputs or factors of production. One of the inputs that must be present is the use of corn seeds. Without the presence of corn seeds, the sweet corn cultivation activities could not be carried out.

The use of inputs and outputs can be written into a production function. From this production function, we can find out how the position of using input in this sweet corn cultivation activity. It has reached the optimal point or not.

In accordance with the theory of production, a good production function can describe "the law of diminishing returns." From this law, the right production function is at least a quadratic equation, and the author tries to find the cube polynomial production function.

The results of the author's research on sweet corn cultivation in Manunggal Jaya Village, Tenggarong Seberang District produce a production function that occurs is a linear production function, $Y=2.5833 \mathrm{X}$. This equation shows that the production activities have not reached an optimal point.
\end{abstract}

Keywords: sweet corn, production function, cube polynomial equation.

\section{PENDAHULUAN}

Jagung merupakan salah satu tanaman yang dikelompokkan sebagai tanaman pangan dan merupakan salah satu makanan pokok beberapa masyarakat di Indonesia. Jagung tergolong dalam makanan pokok biji-bijian, selain serealia, dan umbi-umbian. Sebagai tanaman yang tergolong tanaman pangan dan menjadi salah satu dari beberapa makanan pokok di Indonesia selain beras dan ubi, maka produksi jagung menjadi perhatian khusus bagi Kementrian Pertanian Indonesia untuk dijaga tingkat produksinya.

Jagung juga banyak dikonsumsi oleh masyarakat umum secara langung maupun tidak langsung. Jagung dapat langsung dikonsumsi dengan cara direbus atau dibakar maupun secara tidak langsung menjadi salah satu bahan baku masakan sayur olahan. 
Produksi jagung Indonesia secara nasional berdasarkan data dari Statistik Petanian 2018 Kementrian Pertanian Republik Indonesia menunjukkan pertambahan produksi yang semakin besar dari tahun ke tahun. Pada tahun 2014 produksi jagung nasional sebesar 19 juta ton, lalu menjadi sekitar 19,6 juta ton pada tahun 2015. Pada taun 2016 meningkat pesat menjadi sekitar 23,5 juta ton, dan pada tahun 2017 menjadi sekitar 29,8 juta ton. Pada tahun 2018 diperkirakan produksi jagung menjadi sekitar 30 juta ton setahun.

Propinsi Kalimantan Timur menjadi salah satu propinsi yang sedang giat melakukan penaman jagung pada lahan pertaniannya. Produksi jagung secara keseluruhan di Kalimantan Timur sejak tahun 2014 hingga tahun 2018 berturut-turut adalah 7.500 ton, 8.300 ton, 22.100 ton, 56.500 ton, dan 88.100 ton. Produksi jagung di Kalimantan Timur ini sangat signifikan pertumbuhannya. Salah satu faktor yang mendorong meningkat pesatnya produksi jagung di propinsi ini adalah adanya gerakan menanam jagung. Gerakan menanam jagung ini juga umum dikenal sebagai Program Revolusi Jagung. Salah satu kabupaten yang giat melaksanakan program ini adalah Kabupaten Kutai Kartanegara.

Program Revolusi Jagung adalah salah satu program prioritas yang menjadi bagian strategi dalam trasformasi perekonomian Pemerintah Kabupaten Kutai Kartanegara dari sumber daya yang tidak terbarukan (unrenewable resources) kepada sumber daya yang dapat terbarukan (renewable resources) khususnya sektorpertanian dalam arti luas dan pariwisata ( https://humas.kukarkab.go.id/berita/kemasyarakatan/pemkab-kukar-dukung-program-

revolusi-jagung ). Berdasar informasi yang diperoleh dari tautan berita pada laman https://kaltim.tribunnews.com/2018/11/28/kukar-sudah-swasembada-jagung-produksi-

hampir-8000-ton mengatakan bahwa produksi jagung di Kabupaten Kutai Kartanegara mencapai 13.000 ton pada tahun 2017 meningkat pesat dibandingkan tahun 2016 yang sebesar 3.000 ton. Saat ini luasan tanaman jagung di Kutai Kartanegara sekitar 9.000 hektar.

Varietas yang banyak ditanam oleh petani di Kabupaten Kutai Kartanegara adalah varietas jagung hibrida. Jenis ini diharapkan dapat memberikan hasil yang tinggi dalam produksinya. Selanjutnya hasil panennya dapat langsung dimanfaatkan untuk konsumsi atau sebagai bahan baku bagi industri selanjutnya. Selain jenis hibrida yang umumnya dipanen tua, jenis atau verietas lain yang ditanam petani adalah jagung manis (Zea mays saccarata Linn). Jagung jenis ini umumnya dimanfaatkan untuk dikonsumsi langsung ataupun menjadi bahan campuran dalam membuat masakan/sayuran. Jenis jagung manis saat ini banyak dijumpai di pasar-pasar yang menjual sayuran. 
Salah satu daerah penghasil jagung manis adalah Desa Manunggal Jaya. Desa Manunggal Jaya terletak di Kecamatan Tenggarong Seberang, Kabupatern Kutai Kartanegara. Di desa ini ada sekitar 280 orang berprofesi sebagai petani, dan dari data ini beberapa petani menanam jangung manis sebagai komoditas pertaniannya. Petani yang menanam jagung manis umumnya menggunakan benih sesuai kebiasaan tanpa mengetahui pada tingkat berapakan benih akan memberikan hasil yang paling tinggi.

Berdasarkan hal tersebut di atas maka penulis memiliki tujuan sebagai berikut:

1. Menyusun sebuah fungsi produksi yang terjadi pada produksi jagung manis di Desa Manunggal Jaya menggunakan pendekatan persamaan polinomial untuk dapat menentukan tingkat penggunaan benih yang paling tepat untuk menghasilkan jagung manis yang paling tinggi.

2. Mengetahui apakah produksi jagung di Desa Manunggal Jaya telah mencapai tingkat produksi yang optimal atau belum.

\section{KAJIAN TEORI}

Suatu kegiatan memproses input (faktor produksi) menjadi output pada dasarnya mengikuti hukum “The Law of Diminishing Marginal Return”. Hukum ini mengatakan apabila satu input ditambah terus menerus dan input lain tetap, maka tambahan hasil produksi semula-mula meningkat, setelah mencapai puncak maka produksinya akan menurun.

Proses perubahan input menjadi output dituangkan ke dalam fungsi produksi sebagai berikut:

$$
\mathrm{Y}=\mathrm{f}\left(\mathrm{X}_{1}, \mathrm{X}_{2}, \mathrm{X}_{3}, \ldots . . \mathrm{X}_{\mathrm{n}}\right)
$$

Di mana $\mathrm{Y}$ adalah output dan $\mathrm{X}_{1}$ sampai $\mathrm{X}_{\mathrm{n}}$ adalah input atau faktor produksi. Fungsi produksi tersebut harus memenuhi hukum produksi yang telah disebutkan di atas, sehingga dalam bentuk matematis minimal harus berpangkat 2 (persamaan kuadratik). Persamaan kuadratik berbentuk parabola sehingga memiliki garis naik, titik puncak, dan garis menurun.

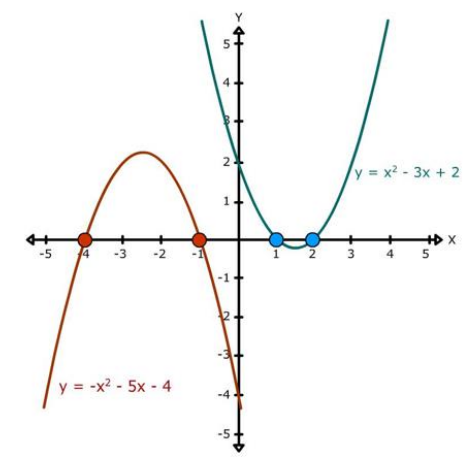

Gambar 1. Gambar Fungsi Kuadrat 


\section{METODE PENELITIAN}

\section{Waktu Penelitian dan Sampel}

Penelitian ini berdasar data yang diperoleh dari petani yang menanam jagung manis di Desa Manunggal Jaya, Kecamatan Tenggarong Seberang, Kabupaten Kutai Kartanegara pada tahun 2012. Jumlah petani yang dijadikan sebagai responden berjumlah 32 responden. Selanjutnya penulis melakukan pengolahan data dengan menggunakan beberapa asumsi sehingga diperoleh data sejumlah 8 kombinasi penggunaan input dan output.

\section{Alat Analisis}

Penulis menggunakan dasar teori produksi di mana akan digunakan fungsi produksi dan kurva produksi. Fungsi produksi adalah suatu fungsi atau persamaan yang menunjukkan hubungan antara tingkat output dan tingkat penggunaan input. Fungsi produksi umumnya ditulis dengan:

$$
\mathrm{Y}=\mathrm{f}\left(\mathrm{X}_{1}, \mathrm{X}_{2}, \mathrm{X}_{3}, \ldots . \mathrm{X}_{\mathrm{n}}\right)
$$

Di mana $\mathrm{Y}$ adalah hasil produksi, dan $\mathrm{X}$ adalah faktor produksi. $\mathrm{Y}$ juga sering ditulis sebagai TPP (Total Physical Product). Penulis melakukan penyederhanaan pada fungsi produksi dengan hanya menggunakan satu faktor produksi saja yaitu penggunaan benih, dan faktor lain carteris paribus. Satuan luas untuk seluruh responden adalah satu hektar, hal ini penulis lakukan untuk pendekatan penggunaan bibit agar sama antar responden. Fungsi produksi yang akan digunakan penulis untuk analisis adalah sebagai berikut:

$$
\mathrm{Y}=\mathrm{f}(\mathrm{X})
$$

Selanjutnya penulis menggunakan pendekatan kurva produksi klasik. Pemilihan kurva produksi klasik karena penulis beranggapan bahwa dalam produksi komoditas pertanian berlaku hukum The Law of Dinimishing Marginal Rerturn atau hukum pertambahan hasil yang semakin berkurang seperti yang tergambar di bawah ini: 


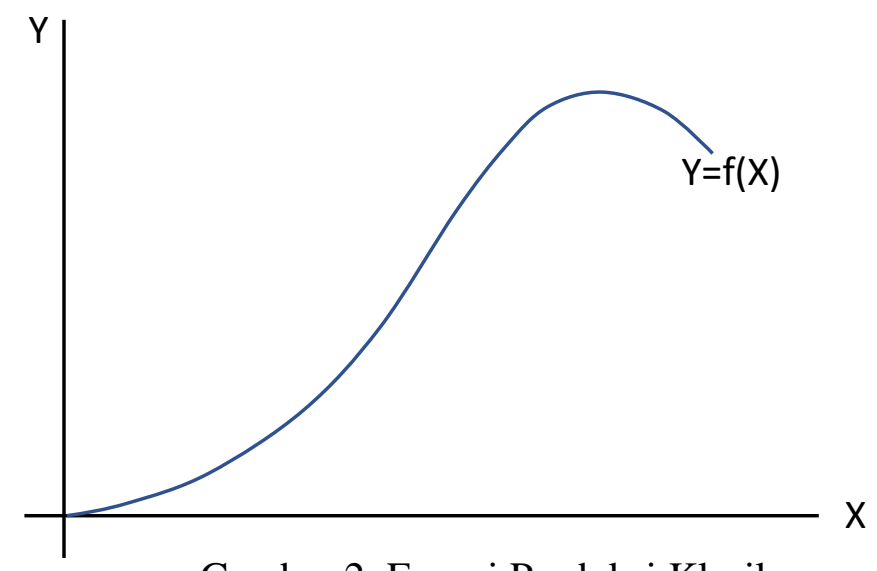

Gambar 2. Fungsi Produksi Klasik

Berdasarkan kurva produksi klasik tersebut di atas, maka penulis beranggapan bahwa pendekatan yang tepat untuk menentukan fungsi produksi adalah pendekatan persamaan polinomial pangkat 3. Persamaan polinomial berpangkat 3 lebih merepresentasikan gambar kurva di atas dibandingkan dengan persamaan kuadrat saja.

Kurva produksi klasik dapat dijabarkan menjadi kurva produksi rata-rata (APP=Average Physical Product) dan produksi marginal (MPP=Marginal Physical Product). Kedua kurva ini penting digunakan untuk menentukan besarnya nilai elastisitas produksi (Ep) dan juga untuk membatasi tahapan produksi yang rasional maupun tidak rasional.

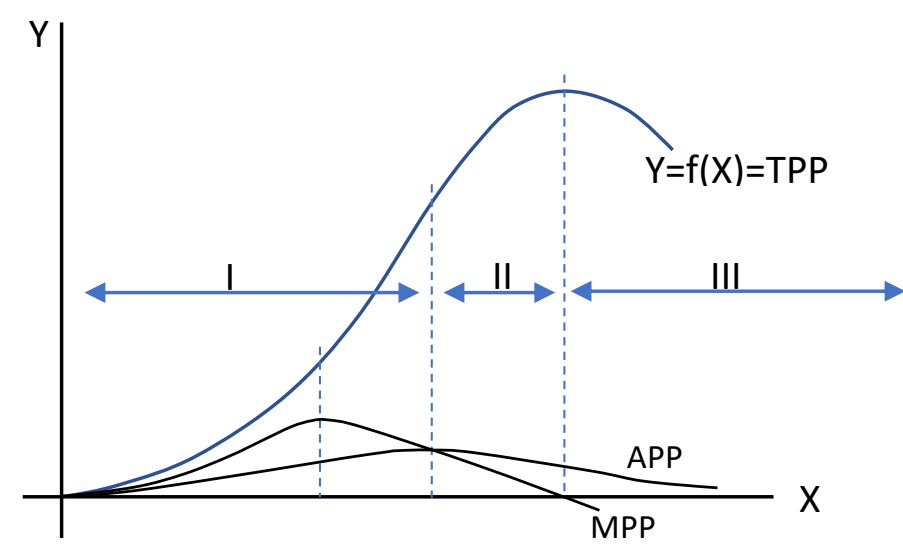

Gambar 3. Fungsi Produksi TPP=Y, APP, dan MPP

Dari Gambar 2 di atas kita dapat melihat batasan daerah yang tidak rasional (daerah I da III) juga daerah produksi yang rasional (daerah II). Harapan ideal adalah petani dapat berproduksi pada daerah tahapan produksi rasional. 
Penulis menggunakan interpolasi polinom berpangkat 3 (interpolasi kubik) untuk menentukan fungsi produksi kurva di atas. Penulis hanya menggunakan 2 variabel saja dalam menyusun persamaan produksi tersebut, yaitu variabel $\mathrm{Y}$ atau output dan variabel $\mathrm{X}$ untuk input-nya.

Penyusunan fungsi polinomial dilakukan dengan cara interpolasi kubik seperti disampaikan oleh Munir, R sebagai berikut:

a. Menentukan fungsi akhir yang dituju:

$P_{3}(x)=a_{0}+a_{1} X+a_{2} X^{2}+a_{3} X^{3}$

b. Polinom $\mathrm{P}_{3}(\mathrm{x})$ ditentukan dengan cara berikut:

misalkan ada 4 titik, lalu kita masukkan titik $\left(\mathrm{x}_{\mathrm{i}}, \mathrm{y}_{\mathrm{i}}\right)$ tersebut ke dalam persamaan $(\mathrm{P} 1)$, $\mathrm{i}=0,1,2,3$. Akan kita dapatkan empat buah persamaan dengan empat buah parameter yang tidak diketahui, yaitu $\mathrm{a}_{0}, \mathrm{a}_{1}, \mathrm{a}_{2}$, dan $\mathrm{a}_{3}$ :

$$
\begin{aligned}
& a_{0}+a_{1} X_{0}+a_{2} X_{0}^{2}+a_{3} X_{0}^{3}=y_{0} \\
& a_{0}+a_{1} X_{1}+a_{2} X_{1}^{2}+a_{3} X_{1}^{3}=y_{1} \\
& a_{0}+a_{1} X_{2}+a_{2} X_{2}^{2}+a_{3} X_{2}^{3}=y_{2} \\
& a_{0}+a_{1} X_{3}+a_{2} X_{3}^{2}+a_{3} X_{3}^{3}=y_{3}
\end{aligned}
$$

c. Selanjutnya kita menghitung nilai $a_{0}, a_{1}, a_{2}$, dan $a_{3}$ dari sistim persamaan tersebut dengan metode eliminasi Gauss-Jordan. Hasil perhitungannya kita masukkan ke dalam persamaan $(\mathrm{P} 3)$.

Penulis menggunakan bantuan software untuk melakukan eliminasi Gauss-Jordan yang terdapat pada laman https://onlinemschool.com/math/assistance/equation/gaus/ dan https://matrix.reshish.com/gauss-jordanElimination.php

Selain itu penulis juga akan menggunakan bantuan software Excel sebagai pembanding dalam menyusun tren polinomial.

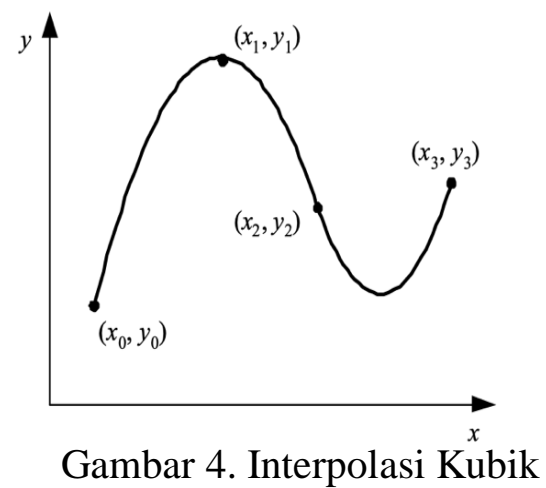


Fungsi polinomial berpangkat tiga yang akan disusun menggunakan beberapa titik-titik produksi-input yang diambil dari data yang tersedia.

\section{HASIL DAN PEMBAHASAN}

Penulis melakukan penelitian lanjutan berdasar data produksi jagung yang diambil di Desa Manunggal Jaya, Kecamatan Tenggarong Seberang, Kabupaten Kutai Kartanegara pada tahun 2012. Data ini selanjutanya penulis susun menjadi beberapa data yang akan menjadi titik pada bidang cartesius yang menunjukkan titik kombinasi input dan hasil (x,y).

Penulis juga menggunakan definisi dan asumsi dalam mengolah data responden yang ada sebagai berikut:

1. Input yang dimaksud penulis adalah jumlah benih jagung yang digunakan tanpa memandang apakah benih tersebut merupakan benih betina maupun jantan. Satuannya adalah kilogram per hektar.

2. Hasil yang dimaksud penulis adalah berat jagung manis saat panen dalam satuan kwintal per hektar.

3. Luasan lahan yang dipergunakan oleh responden petani jagung untuk produksi jagung adalah seluas 1 hektar (Ha).

Jumlah keseluruhan responden adalah 32 petani dan setelah penulis lakukan pengelompokan data maka diperoleh 8 buah titik kombinasi jumlah input dan jumlah produksi yang terjadi. Adapun kedelapan kombinasi tersebut tersaji pada tabel berikut:

Tabel 1.

Data Input Benih dan Hasil Jagung

\begin{tabular}{ccc}
\hline NO. & $\begin{array}{c}\text { BENIH Kg } \\
(\mathbf{X})\end{array}$ & $\begin{array}{c}\text { PRODUKSI } \\
\text { Kwintal } \\
(\mathbf{Y})\end{array}$ \\
\hline 1 & 3 & 7,75 \\
\hline 2 & 6 & 15,50 \\
\hline 3 & 9 & 23,25 \\
\hline 4 & 12 & 31,00 \\
\hline 5 & 15 & 38,75 \\
\hline 6 & 18 & 46,50 \\
\hline 7 & 21 & 54,25 \\
\hline 8 & 24 & 62,00
\end{tabular}

Sumber : Data primer, diolah 
Titik-titik input-hasil yaitu $(3 ; 7,75),(6 ; 15,5),(9 ; 23,25),(12 ; 31),(15 ; 38,75),(21 ; 54,25)$, dan $(24 ; 62)$. Selanjutnya dari 8 titik kombinasi jumlah input dan jumlah produksi di atas disusun menjadi pesamaan poninom kubik seperti yang telah disampaikan pada bagian atas yaitu mengikuti pola persamaan P3. Untuk nilai ao penulis menetapkan bernilai 0 karena produksi jagung tidak akan memberikan hasil produksi tanpa adanya jumlah benih yang digunakan. Kedelapan persamaan yang dapat dibentuk dari titik kombinasi tersebut adalah:

$$
\begin{array}{llll}
0+a_{1}(3)+a_{2}(3)^{2}+a_{3}(3)^{3} & = & 7,75 \\
0+a_{1}(6)+a_{2}(6)^{2}+a_{3}(6)^{3} & = & 15,5 \\
0+a_{1}(9)+a_{2}(9)^{2}+a_{3}(9)^{3} & = & 23,25 \\
0+a_{1}(12)+a_{2}(12)^{2}+a_{3}(2)^{3} & = & 31,0 \\
0+a_{1}(15)+a_{2}(15)^{2}+a_{3}(15)^{3} & = & 38,75 \\
0+a_{1}(18)+a_{2}(18)^{2}+a_{3}(18)^{3} & = & 46,5 \\
0+a_{1}(21)+a_{2}(21)^{2}+a_{3}(21)^{3} & = & 54,25 \\
0+a_{1}(24)+a_{2}(24)^{2}+a_{3}(24)^{3} & = & 62,0
\end{array}
$$

Dari kedelapan persamaan di atas penulis mencari nilai dari $\mathrm{a}_{1}, \mathrm{a}_{2}$, dan $\mathrm{a}_{3}$ menggunakan eliminasi Gauss-Jordan. Eliminasi ini penulis lakukan menggunakan software online pada dua laman yang telah penulis sebutkan sebelumnya. Hasil dari kedua laman tersebut sebagai berikut:

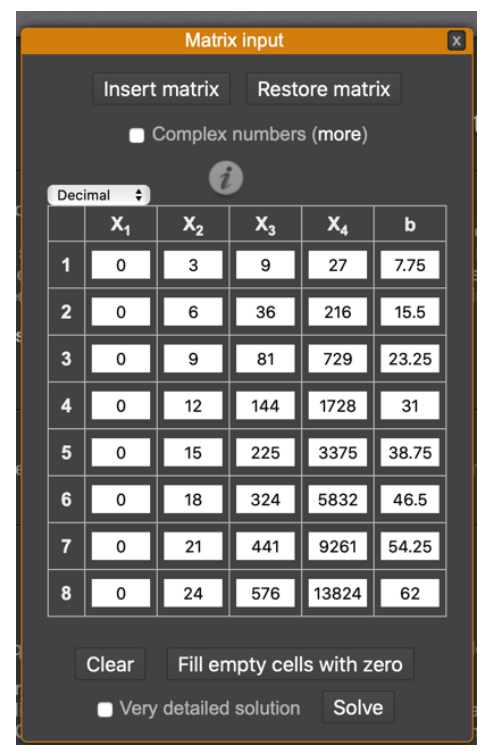

Gambar 4 dan 5. Eliminasi Gauss-Jordan pada laman https://matrix.reshish.com/gaussjordanElimination.php 


\section{Solution:}

$$
\begin{array}{|ll}
3 x_{2}+9 x_{3}+27 x_{4}=7.75 & \text { Answer: } \\
6 x_{2}+36 x_{3}+216 x_{4}=15.5 & \text { The system of equations has a solution set: } \\
9 x_{2}+81 x_{3}+729 x_{4}=23.25 & \left\{\begin{array}{l}
x_{2}=\frac{31}{12} \\
12 x_{2}+144 x_{3}+1728 x_{4}=31 \\
15 x_{2}+225 x_{3}+3375 x_{4}=38.75 \\
18 x_{2}+324 x_{3}+5832 x_{4}=46.5
\end{array}\right. \\
x_{4}=0
\end{array}
$$

Gambar 6 dan 7. Eliminasi Gauss-Jordan pada laman

\section{https://onlinemschool.com/math/assistance/equation/gaus/}

Untuk hasil pengolahan data pada Gambar 6 dan Gambar 7, penulis hanya bisa memasukkan 6 buah persamaan saja karena keterbatasan jumlah persamaan yang disediakan pada laman.

Nilai $\mathrm{x}_{2}$ pada hasil eliminasi persamaan menggunakan metode Gauss-Jordan adalah nilai $a_{1}$ pada persamaan $P 3$ yaitu $\mathrm{P}_{3}(\mathrm{x})=\mathrm{a}_{0}+\mathrm{a}_{1} \mathrm{X}+\mathrm{a}_{2} \mathrm{X}^{2}+\mathrm{a}_{3} \mathrm{X}^{3}$. Nilai hasil $\mathrm{x}_{3}$ merupakan nilai $\mathrm{a}_{2}$ dan nilai hasil $\mathrm{x}_{4}$ adalah nilai a 3 pada persamaan $\mathrm{P} 3$. Nilai a ditentukan sebesar 0 karena tanaman jagung tidak akan memberikan hasil tanpa adanya benih yang digunakan

Hasil interpetasi ini disusun menjadi sebuah persamaan polinomial kubik sebagai berikut:

$$
\begin{gathered}
\mathrm{Y}=0+2,5833 \mathrm{X}+0 . \mathrm{X}^{2}+0 . \mathrm{X}^{3} \\
\text { atau } \\
\mathrm{Y}=2,5833 \mathrm{X}
\end{gathered}
$$

Persamaan tersebut adalah fungsi produksi yang merupakan berbentuk persamaan linier.

Untuk mencari hasil pembanding dan penggambaran grafik, maka penulis menggunakan bantuan perangkat lunak Excel untuk melakukannya. Gambar grafik serta hasil persamaan polinomial pangkat tiga berdasarkankan hasil perhitungannya tergambar dalam gambar di bawah ini:

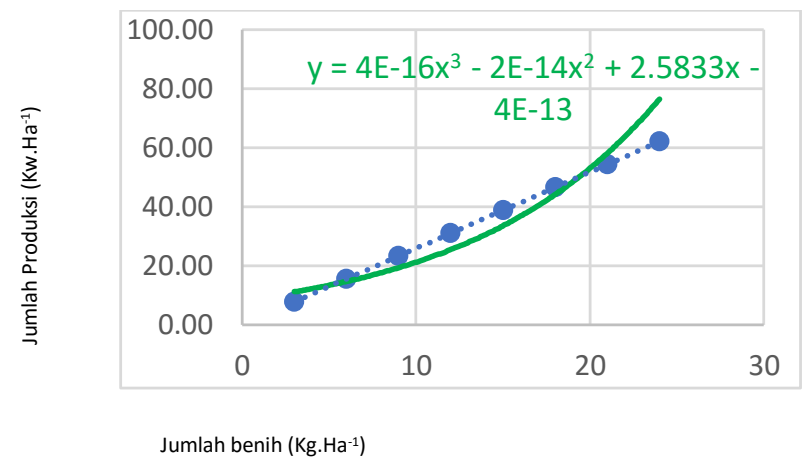

Gambar 8. Gambar Kurva Produksi Jagung Manis dan Fungsi Produksi Polinomialnya 
Hasil persamaan fungsi produksi yang dihasilkan oleh Excel adalah:

$$
Y=-4 E^{-13}+2,5833 X-2 E^{-14} X^{2}+4 E^{-16} X^{3}
$$

Nilai konstanta, variabel di depan $\mathrm{X}^{2}$ dan $\mathrm{X}^{3}$ bernilai sangat kecil sehingga sebenarnya dapat dianggap bernilai 0. Jika nilai konstanta dan variabel di depan $X^{2}$ dan $X^{3}$ dianggap 0 , maka dapat kita susun fungsi produksinya adalah $\mathrm{Y}=2,5833 \mathrm{X}$, sama dengan yang dihasilkan melalui perhitungan di laman daring sebelumnya.

Berdasar hal di atas maka fungsi produksi yang terjadi pada produksi jagung manis di Desa Manuggal Jaya sebenarnya berbentuk garis lurus atau linier. Penambahan jumlah input (X) setiap kilogramnya akan meningkatkan jumlah hasil (Y) sebesar 2,5833 kwintal.

Kondisi yang terjadi berdasar fungsi produksi tersebut sebenarnya masih pada posisi increasing return to scale dimana penambahan 1 satuan input kan memberikan tambahan hasil yang lebih besar dari penambahan 1 satuan inputnya. Jika kegiatan produksi dilihat dari posisi pada tahapan produksi, penulis beranggapan bahwa kegiatan menanam jagung manis di Desa Manunggal Jaya berada pada tahapan I.

Gambar 8 juga menunjukkan kurva produksi polinomial masih berbentuk garis melengkung dengan slope positif. Hal ini sesuai dengan ciri produksi pada tahapan poroduksi I.

\section{PENUTUP}

\section{Kesimpulan}

Dari hasil penyusunan persamaan fungsi produksi polinomial pangkat tiga/kubik maka diperoleh beberapa simpulan sebagai berikut:

1. Fungsi produksi yang terjadi adalah $Y=2,5833 \mathrm{X}$ yang ternyata berbentuk fungsi linier (garis lurus) dan bukan berbentuk fungsi produksi polinomial

2. Diperolehnya fungsi yang linier ini dapat disebabkan oleh data yang ada maupun petani yang belum menggunakan input secara optimal.

3. Petani jagung manis di desa Manunggal Jaya, Kecamatan Tenggarong Seberang, Kabupaten Kutai Kartanegara belum mencapai tingkat penggunaan input yang optimal. Hal ini ditunjukkan oleh posisi produksi masih dalam bentuk kurva yang 
menaik/menanjak dan belum mencapai titik puncak produksi maupun decreasing return.

\section{Saran}

Beberapa saran yang dapat penulis sampaikan berdasarkan simpulan yang diperoleh sebagai berikut:

1. Petani masih dapat menambahkan jumlah penggunaan benih agar hasil produksi lebih tinggi.

2. Untuk penelitian lebih lanjut perlu data yang lebih banyak agar ketepatan fungsi produksi yang dicari dapat tercapai.

\section{DAFTAR PUSTAKA}

Humas.kukarkab.go.id. (2019). Pemkab Kukar Dukung Program Revolusi Jagung. Diakses pada 1 Mei 2020, dari https://humas.kukarkab.go.id/berita/kemasyarakatan/pemkabkukar-dukung-program-revolusi-jagung

Kaltim.tribunnews.com. (2018, 28 Nopember). Kukar Sudah Swasembada Jagung, Produksi Hampir 8.000 Ton. Diakses pada 1 Mei 2020, dari https://kaltim.tribunnews.com/2018/11/28/kukar-sudah-swasembada-jagung-produksihampir-8000-ton

Matrix.reshish.com. Gauss-Jordan Elimination Calculator. Diakese pada 15 Mei 2020, dari https://matrix.reshish.com/gauss-jordanElimination.php

Onlineemschool.com. Gaussian Elimination Calculator. Diakeses pada 10 Mei 2020, dari https://onlinemschool.com/math/assistance/equation/gaus/

Rinaldi Munir, Bahan Kuliah IF4058 Topik Khusus Informatika I, ITB

Rosiana, D. 2012. Analisis Pengaruh Faktor Produksi Terhadap Produkstivitas Jagung Manis (Zea Mays Saccharata Start) Di Desa Manunggal Jaya Kecamatan Tenggarong Seberang Kabupaten Kutai Kartanegara, Skripsi, Universitas Kutai Kartanegara. 